\title{
Saint-Lô - Technopole Agglo 21
}

$n^{\circ} 3378$

\section{David Flotté}

\section{(2) OpenEdition}

Journals

Édition électronique

URL : http://journals.openedition.org/adlfi/16785

ISSN : 2114-0502

Éditeur

Ministère de la culture

Référence électronique

David Flotté, "Saint-Lô - Technopole Agglo 21 », ADLFI. Archéologie de la France - Informations [En ligne], Basse-Normandie, mis en ligne le 26 février 2016, consulté le 19 avril 2019. URL : http:// journals.openedition.org/adlfi/16785

Ce document a été généré automatiquement le 19 avril 2019

(c) Ministère de la Culture et de la Communication, CNRS 


\section{Saint-Lô - Technopole Agglo 21}

$n^{\circ} 3378$

\section{David Flotté}

Lien Atlas (MCC) :

http://atlas.patrimoines.culture.fr/atlas/trunk/index.php?

ap_theme=DOM_2.01.02\&ap_bbox=-1.127;49.085;-1.036;49.139

1 Le projet de Saint-Lô Agglomération d'aménager 14,66 ha en zone d'activités (projet technopole agglo 21, $1^{\text {re }}$ tranche) sur le territoire de la commune de Saint-Lô a donné lieu à l'émission d'un arrêté de prescription de diagnostic archéologique (arrêté $\mathrm{n}$ - 162013095 du 11 mars 2013). Ces terrains se trouvent le long et au sud de la RD 972 (route de Saint-Lô à Coutances) et de part et d'autre de la RD 559. Ils occupent le sommet du versant de la vallée du Fumichon, un affluent de la Vire, et forment un léger vallon. Ils culminent à $88 \mathrm{~m}$ NGF à l'ouest de l'emprise et à $69 \mathrm{~m}$ à l'est. La pente moyenne entre ces deux points est de $4 \%$.

2 Hormis quelques fosses erratiques à fonction indéterminée pour la plupart, les découvertes faites au cours du diagnostic consistent en 112 tronçons de fossés, de largeurs et profondeurs modestes, uniformément comblés de limon brun-gris et n'ayant livré aucun mobilier archéologique. On peut donc s'attendre à ce qu'aucune occupation domestique en relation avec les fossés ne se trouve sur l'emprise du diagnostic.

La plupart des fossés reconnus sous une forme fossile s'inscrivent dans les orientations parcellaires actuelles. Ils témoignent donc d'états antérieurs (démembrements, remembrements) de la phase parcellaire aujourd'hui active. Le cadastre de 1834 témoigne du fait que cette phase parcellaire (fossés, talus et chemins) est en place à cette époque, quasiment sous la même forme qu'aujourd'hui. La période et le mode de mise en place de cette organisation parcellaire restent en revanche inconnus.

4 Un peu moins d'une dizaine de fossés semblent en désaccord avec la phase parcellaire actuelle. Ils ont les mêmes caractéristiques morphologiques que les autres, mais n'apparaissent que sous la forme d'occurrences uniques. Ils sont clairsemés et ne 
paraissent pas suivre une orientation dominante ou s'organiser en une trame, ce qui empêche de les associer au sein d'une même phase parcellaire.

INDEX

Index géographique : Basse-Normandie, Manche (50), Saint-Lô

Index chronologique : Indéterminée

operation Diagnostic (EV)

Mots-clés : fossé

\section{AUTEURS}

DAVID FLOTTÉ

Inrap 